\title{
Labor investigadora en el Registro Andaluz de Arquitectura Contemporánea
}

Mar Loren Méndez, Grupo de Investigación HUM-666 “Ciudad, Patrimonio y Arquitectura contemporánea en Andalucía”. Universidad de Sevilla

\author{
La investigación se \\ estructura a partir de \\ ocho equipos \\ provinciales para \\ alcanzar un equilibrio \\ territorial
}

El triple objetivo planteado en el marco del RAAC -documentación, protección y difusión- sienta las bases en un riguroso proceso de investigación que comienza su andadura en 2004. Dicha labor investigadora se vertebra con la colaboración del Grupo de Investigación HUM-666 "Ciudad, Patrimonio y Arquitectura contemporánea en Andalucía" cuyo encargado es Víctor Pérez Escolano, con una larga trayectoria en tareas de catalogación y protección. La decisión de estructurar la investigación a partir de los ocho equipos provinciales parte del objetivo de alcanzar un equilibrio territorial de la producción arquitectónica de Andalucía. Los organismos de la Consejería de Cultura promotores del proyecto -IAPH (Instituto Andaluz de Patrimonio Histórico) y DGBC (Dirección General de Bienes Culturales)- trabajan conjuntamente junto con el equipo de investigadores en la toma de decisiones y en la elaboración documental, conformando un grupo de trabajo de mayor entidad. Partiendo de una exposición general que ha guiado la elaboración del RAAC, el caso de Málaga se instrumentaliza en este artículo para ejemplificar el proceso investigador.

\section{Estado de la cuestión}

En una primera fase los equipos provinciales realizan una búsqueda de los inmuebles anda- luces del siglo XX que ya han sido valorados, catalogados o protegidos. La elaboración del estado de la cuestión aborda:

$\rightarrow$ Un primer vaciado bibliográfico, en el que se estudian en primera instancia las publicaciones de carácter más general sobre arquitectura contemporánea andaluza, guías de arquitectura, y en algunos casos publicaciones monográficas de un autor muy vinculado a una provincia (el caso de Rafael de la Hoz en Córdoba es paradigmático) o de una producción programática que caracteriza una provincia (el caso de la arquitectura turística en Málaga o la arquitectura pública en Sevilla). Existen provincias, como es el caso de Sevilla, que están más estudiadas que el resto produciendo en las bibliografías de ámbito andaluz un desequilibrio territorial. Frente al esfuerzo de difusión sevillana, en Málaga encontramos obras de gran calidad con escasísima presencia bibliográfica; el Conjunto Eurosol en Torremolinos del mismo Rafael de la Hoz, capaz de marcar la producción cordobesa, en el ámbito malagueño queda eclipsado por el uso turístico al que se destina. Fernando Higueras que logra reconocimiento con su arquitectura turística en otros 
(- Instituto Ntra. Sra. de la Victoria, en Málaga. Proyecto de Miguel Fisac Serna de 1953 / Archivo Fundación Miguel Fisac Serna, Colegio Oficial de Arquitectos de Ciudad. ReAl. ARQYestudio

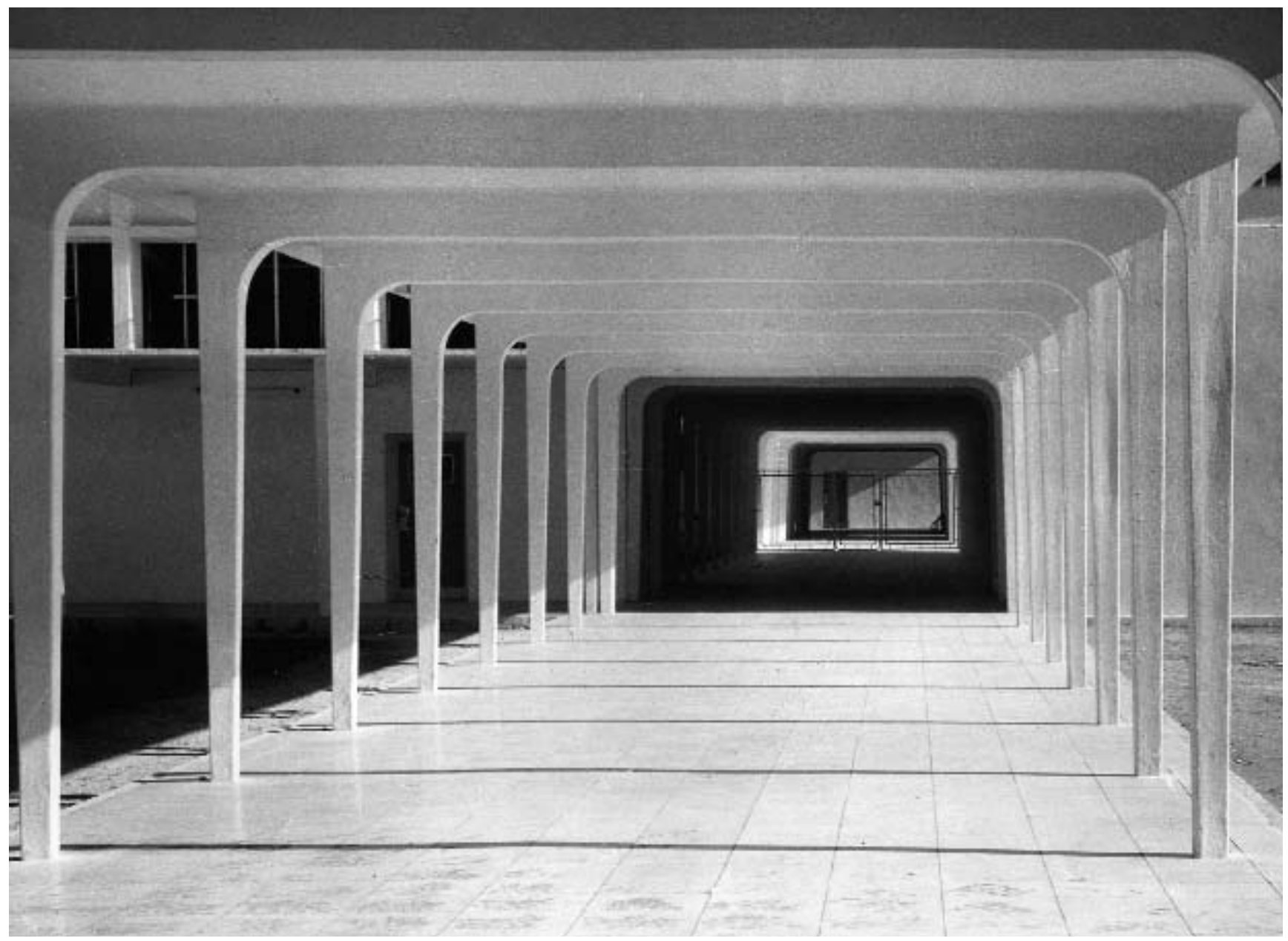


ámbitos nacionales -el hotel Las Salinas en Lanzarote está protegido desde 1998tiene obras de gran calidad en Andalucía como es el edificio residencial las Terrazas de las Lomas del Marbella Club y que sólo aparece en la bibliografía monográfica del autor. El mismo tratamiento de producción periférica y poco integrada en la bibliografía general andaluza sufren provincias como Almería, Jaén y Huelva; en este caso agravado por la escala reducida de sus capitales.

$\rightarrow$ Una revisión de los catálogos de protección de ámbito municipal. La presencia de inmuebles del siglo XX es muy escasa, a excepción de aquellas arquitecturas de corte historicista y regionalista de principios de siglo. Estas, sin embargo, aparecen documentadas desde análisis muy formalistas. Paradójicamente, y salvo casos excepcionales como la producción sevillana de Aníbal González, son las más obviadas en las publicaciones de arquitectura contemporánea andaluza y requieren su incorporación certera al discurso contemporáneo. La producción de Ángel Casas en Granada o de Guerrero Strachan en Málaga queda limitada a los catálogos de protección, guías o publicaciones monográficas.

La coherencia y revisión que este estudio debe guardar con las labores de catalogación y protección desarrolladas con anterioridad por el IAPH y la DGBC es un objetivo obligado:

$\rightarrow$ Se realiza un estudio de los inmuebles contemplados por el DOCOMOMO con el fin de incorporar los esfuerzos del IAPH, miembro del citado organismo.

$\rightarrow$ Se incorpora al estudio todos aquellos inmuebles de los que existía un expediente de protección abierto por parte de la DGBC.

En esta primera aproximación queda patente la ausencia en el marco general de la arquitectura contemporánea andaluza de piezas indispensables para entender su producción edilicia, la ocupación urbana y territorial. Son arquitecturas olvidadas en la bibliografía andaluza reciente, que en el pasado sólo aparecieron puntualmente y que ahora se incorporan para mostrar nuestro patrimonio en toda su dimensión y complejidad. Es el caso de la Casa de Bernard Rudofsky en Frigiliana, una obra desconocida en los ámbitos locales -aún cuando valorada en la actualidad a nivel internacional- y ausente en la bibliografía contemporánea andaluza.

\section{Documentación gráfica de los bienes. Documentación in situ y búsqueda en archivos}

Una vez realizada esta primera aproximación se comienza el trabajo de campo. Es importante puntualizar que tanto la labor bibliográfica como el trabajo de campo son tareas que acompañan a todo el proceso de documentación del trabajo. Cuando se documenta un inmueble se procede a la búsqueda bibliográfica monográfica y se realizan las visitas necesarias para su documentación y análisis una vez ha pasado a formar parte del registro.

En esta fase de documentación gráfica es imprescindible tener en cuenta la doble vertiente del proyecto; la elaboración del registro y su protección autonómica requieren una valoración del bien patrimonial que abarque los diversos matices y objetivos de ambos procesos documentales. En este aspecto la descripción fotográfica general necesaria para el registro de los bienes ha de ser más exhaustiva para los 240 bienes a proteger, siendo imprescindible exponer con claridad el estado actual de las mismas y las transformaciones sufridas. Por ello, es importante aportar fotografías actualizadas junto con imágenes históricas e información planimétrica, documentando de forma rigurosa la vida del inmueble. La documentación inédita encontrada en archivos como el edificio docente de Miguel Fisac en Málaga es indispensable para comprender el alcance de sus transformaciones y permitir valorar a la DGBC su protección.
Presentación de propuestas. Elaboración del registro. Lecturas transversales

Una vez estructuradas por períodos las propuestas de los diferentes equipos provinciales y decantados los inmuebles con mayor valor patrimonial, se procede a partir de mayo de 2005 a una serie de reuniones junto con el IAPH y la DGBC en las que se presentan las propuestas y se obtiene un primer avance del registro a principios de 2006.

Este estudio se complementa con la incorporación de unas lecturas transversales con el fin de disolver cualquier estanqueidad que pudiera sufrir el estudio debido a la estructuración por provincias. Este ejercicio permite añadir el equilibrio a nivel programático al simplemente territorial. Los equipos cambian su enfoque de carácter geográfico para adentrarse en un análisis de carácter tipológico y de uso realizándose lecturas transversales de vivienda unifamiliar, vivienda plurifamiliar urbana, vivienda social, comercio y transporte, administrativa, ocio y turismo, religiosa, cultura, espectáculos y deporte, docente y obra de rehabilitación. Junto con esta labor será indispensable la incorporación de expertos externos para usos, tipologías o estilos específicos como los poblados de colonización, la arquitectura industrial, la arquitectura ecléctica y regionalista, los jardines y espacios públicos, los cementerios. Quedan así patentes los vacíos y desequilibrios de la primera selección teniendo en cuenta la triple entrada provincial, cronológica y programática. Una vez detectadas las carencias o concentraciones no imputables a la identidad misma del territorio donde se asienta, se procede a solventarlas antes del cierre definitivo del registro, aumentando considerablemente la primera versión del registro. La DGBC añade un análisis geográfico en el que hace una valoración del equilibrio territorial, no sólo comparando las distintas provincias sino ofreciendo una visión global de la geografía andaluza con el fin de detectar zonas que requieren un análisis adicional. 
Documentación. Integración en SIPHA y documentación técnica para catalogaciones genéricas

Desde septiembre de 2006 y una vez establecidos los criterios de definición de los bienes en sus dos niveles de valoración, los equipos proceden a la integración, con la ayuda indispensable del Centro de Documentación del IAPH, de los datos de cada ítem en el SIPHA (Sistema de Información del Patrimonio Histórico de Andalucía). Se incluyen datos básicos del bien (denominación, autor, cronología), descripción, localización, imagen identificativa y bibliografía, información toda accesible desde Internet, proceso que se encuentra prácticamente terminado.

Los 240 bienes seleccionados para su posterior protección son documentados a partir de finales de 2006 de forma más rigurosa y desarrollada; se trata de la redacción de los documentos técnicos que servirán a la DGBC para la potencial catalogación genérica de estos bienes. El texto descriptivo debe incluir una base científica de referencias, incorporando una sección de datos históricos. La delimitación del bien es exhaustiva y justificada y la documentación gráfica debe ser capaz de describir el inmueble y las transformaciones sufridas. La búsqueda documental ha sido una tarea difícil ya que, a diferencia de comunidades como Cataluña, nuestra documentación se encuentra dispersa; archivos privados, ayuntamientos y archivos monográficos de autor o de carácter municipal han sido nuestras principales fuentes.

La Junta de Andalucía, a través de sus organismos promotores, sienta así las bases de una iniciativa pionera, conjugando los esfuerzos de documentación y difusión de nuestra arquitectura del siglo XX con los procesos de protección. Se procede así a la consiguiente incorporación en la conciencia ciudadana del valor que la arquitectura contemporánea posee, completando el escenario patrimonial andaluz identificado tradicionalmente con una historia más lejana.

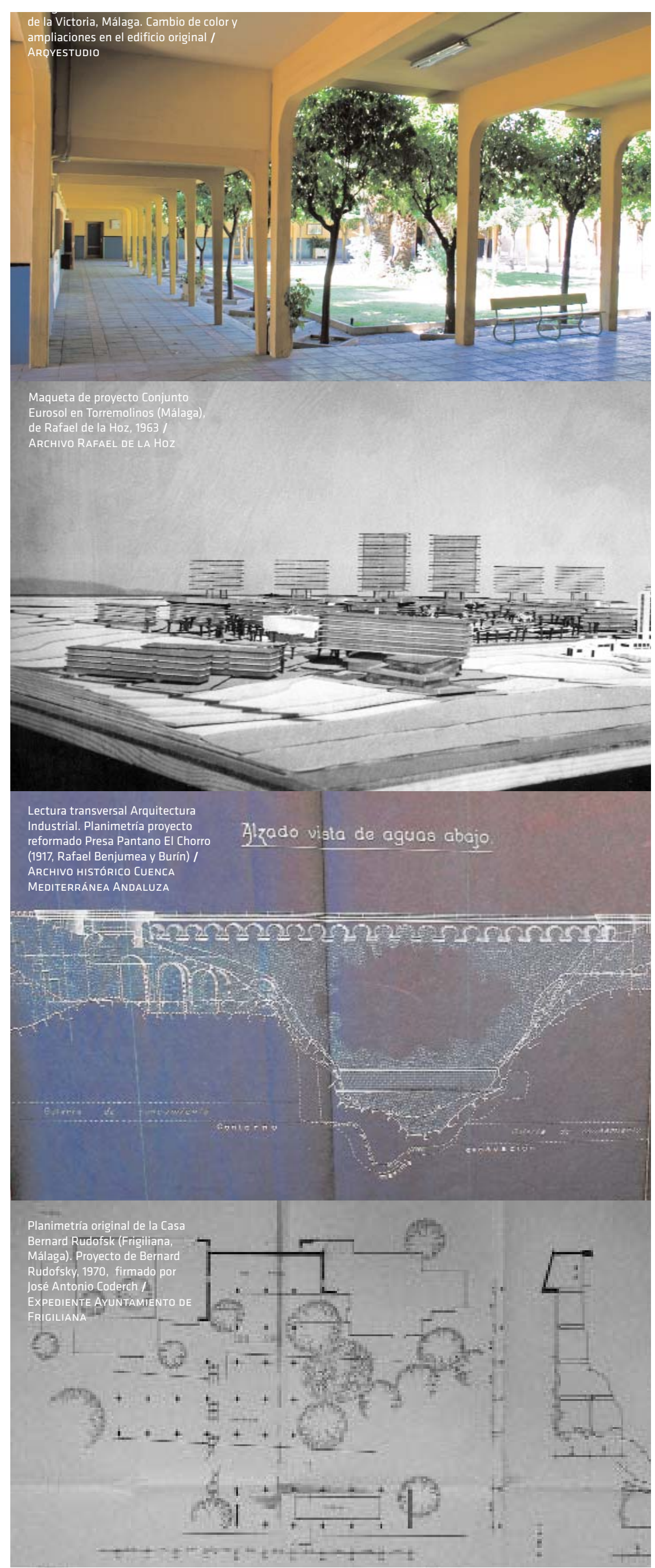


- Teatro Falla en Cádiz, proyecto de Adolfo Morales de los Ríos (1884-1905) / IAPH

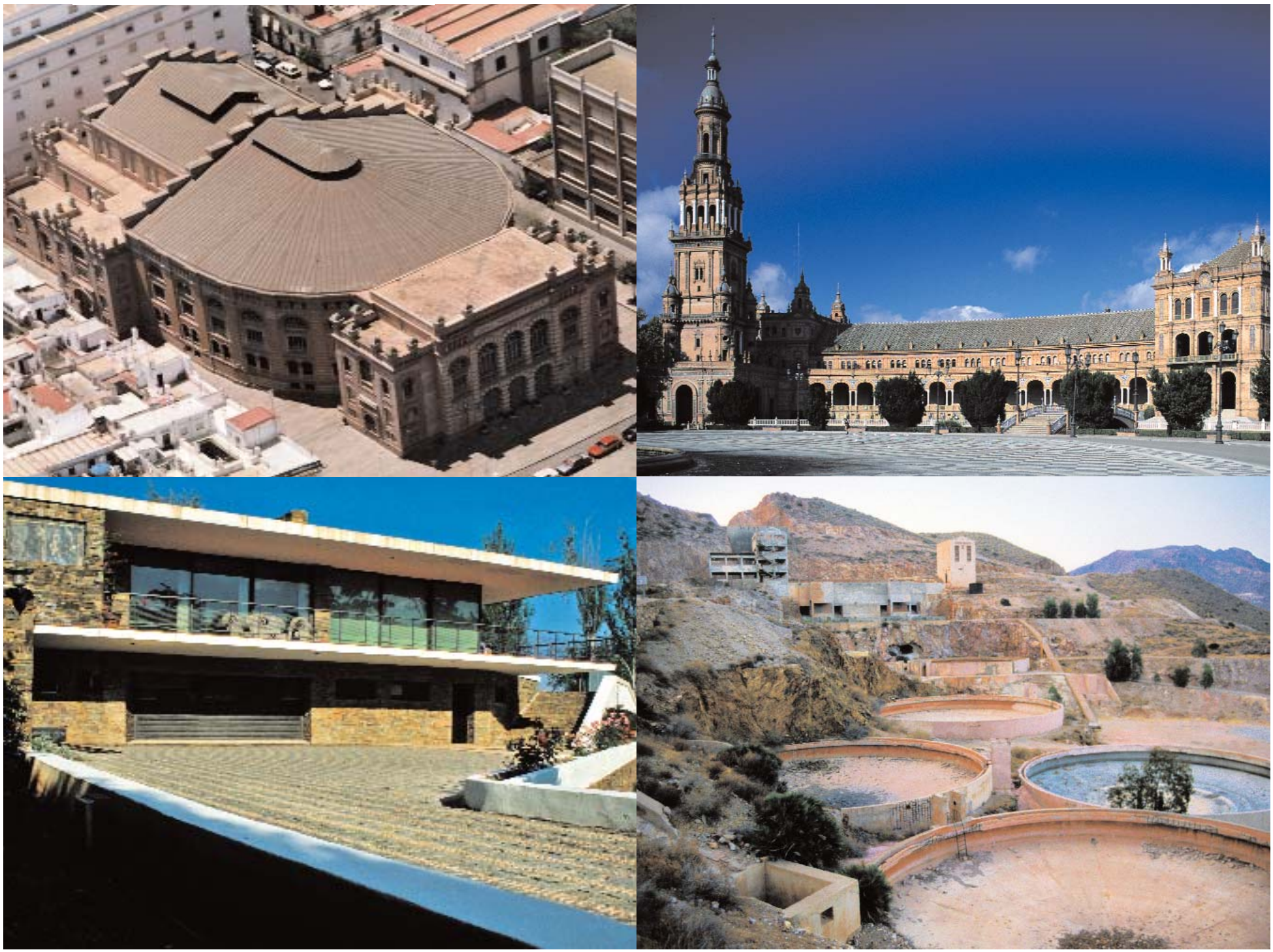

(1) Chalet Canals en Córdoba, obra de Rafael de la Hoz Arderius de 1956 / CARLos ORTEGA, IAPH @ Minas de Rodalquilar en Nijar (Almería) (1954) / ISABEL Dugo, IAPH 